\title{
The Effect of Furosemide on Arterial Blood Pressure, Blood Glucose Levels and Incidence of Heart Arrhythmias
}

\author{
Elvedin Osmanovic ${ }^{1, ~ *, ~ E s e d ~ O m e r k i c ~}{ }^{1}$, Semir Imamovic ${ }^{2}$, Mirza Mukinovic ${ }^{1}$, \\ Halid Mahmutbegovic ${ }^{3}$, Mersiha Cerkezovic ${ }^{4}$ \\ ${ }^{1}$ Emergency Department, Health Center Zivinice, Zivinice, Bosnia and Herzegovina \\ ${ }^{2}$ Department of Anesthesiology and Resuscitation, University Clinical Center Tuzla, Tuzla, Bosnia and Herzegovina \\ ${ }^{3}$ Department of Quality Control, Health Center Zivinice, Zivinice, Bosnia and Herzegovina \\ ${ }^{4}$ Department of Internal Medicine, Health Center Zivinice, Zivinice, Bosnia and Herzegovina
}

Email address:

elveos@hotmail.com (E. Osmanovic)

${ }^{*}$ Corresponding author

\section{To cite this article:}

Elvedin Osmanovic, Esed Omerkic, Semir Imamovic, Mirza Mukinovic, Halid Mahmutbegovic, Mersiha Cerkezovic. The Effect of Furosemide on Arterial Blood Pressure, Blood Glucose Levels and Incidence of Heart Arrhythmias. American Journal of Internal Medicine. Vol. 5, No. 3, 2017, pp. 41-45. doi: 10.11648/j.ajim.20170503.12

Received: March 26, 2017; Accepted: April 5, 2017; Published: April 29, 2017

\begin{abstract}
Furosemide is a diuretic and is often used in the treatment of hypertension. This medicine is very good when it comes to lowering the blood pressure, and this is also a drug of choice when it comes to the stage of hypertensive urgencies and emergencies. It can be administered intravenously, and the effects reach a maximum within 30 minutes. Due to the fact that this medicine causes a loss of potassium ions it can also affect the reduction of insulin in the blood, and thus the increase in blood glucose and arrhythmias. A prospective random study was carried out in Emergency Medical Service of Public Health Institution Center "Zivinice", where we analyzed 120 patients which were suffering from hypertension heart disease, and diabetes. We included all 120 patient whom suffering from hypertension and diabetes starting February till end of July 2016. Data for analysis: age, gender, bodymass index, analysis of the arterial blood pressure value, characteristic laboratory changes, analysis of electrocardiography. Looking at all the three groups of patients, it can be noticed that the maximum value of arterial blood pressure upon arrival at the Emergency Medical service had patients suffering from hypertension and diabetes, where the average value of arterial blood pressure was $173 / 113 \mathrm{mmHg}$. According to analysis for all three observed groups of patients, after treatment with furosemide there is no statistical significance in the incidence of arrhythmias between the groups where. Looking at the summary for all three groups of patients, the average value increase of blood glucose after treatment with furosemide is $0.7 \mathrm{mmol} / \mathrm{l}$. Furosemide is safe for the treatment of hypertension in diabetic patients. It does not cause an increase in blood glucose levels.
\end{abstract}

Keywords: Furosemide, Hypertension, Diabetes, Arrhythmias

\section{Introduction}

Potassium is taken into our body system through food (50$100 \mathrm{mmol} /$ day) and it is distributed in the body fluids in way that the majority $(98 \%)$ of potassium is placed in the cells, i.e. in the cellular fluid, while only $2 \%$ is in the extracellular fluid. The result of that is concentration of potassium in the cellular fluids of $140-150 \mathrm{mmol} / \mathrm{L}$, while in extracellular fluid the concentration is $3.5-5.0 \mathrm{mmol} / \mathrm{L}$. This gradient concentration of potassium is formed and maintained by the
$\mathrm{Na}^{+} / \mathrm{K}^{+}$pumps and relative impermeability of cell membranes for potassium [1].

Insulin enhances operation of the $\mathrm{Na}^{+} / \mathrm{K}^{+}$pumps and in that way enhances entering of potassium into the cell itself, i.e. it reduces the concentration of potassium in the extracellular fluid. In case that potassium becomes low in the body system, this condition leads to hypocalemia that reduces secretion of insulin in the body and as a result of that blood glucose levels increases. Level of potassium also affects the heart rate while potassium deficiency 
(hypocalemia) can lead to fast heart rate. In the ECG potassium deficiency is manifested as supraventricular tachycardia [2].

Furosemide is a diuretic and is often used in the treatment of hypertension. This medicine is very good when it comes to lowering the blood pressure, and this is also a drug of choice when it comes to the stage of hypertensive urgencies and emergencies. It can be administered intravenously, and the effects reach a maximum within 30 minutes. Due to the fact that this medicine causes a loss of potassium ions it can also affect the reduction of insulin in the blood, and thus the increase in blood glucose and arrhythmias [3].

The aim of this paper is:

(1) An effect of furosemide onto hypertension treatment and crises.

(2) To determine hypertensive crises in patients suffering from hypertension and diabetes.

(3) To determine the frequency of arrhythmic heart disorders before and after antihypertensive treatment of furosemide.

(4) To identify the difference in blood glucose levels before and after antihypertensive treatment of furosemide.

\section{Methods}

A prospective random study was carried out in Emergency Medical Service of Public Health Institution Center "Zivinice", where we analyzed 120 patients which were suffering from hypertension heart disease, diabetes or they had high blood pressure without diagnosed hypertension heart disease and diabetes. Patients were divided into 3 groups, each group of 40 persons.

The following groups were formed:

a. the first group of patients which were suffering from hypertension;

b. the second group which includes hypertensive patients who suffered from co-morbidities diabetes;

c. the third (control) group of patients are patients which suffered from high blood pressure, but they have not been diagnosed with hypertension and diabetes.

All three groups of patients in the treatment of hypertension were treated with furosemide twice a day $20 \mathrm{mg}$ $=40 \mathrm{mg}$ iv $(2 \times 20 \mathrm{mg}=40 \mathrm{mg})$. All data about patients were collected and analyzed after approval by the Ethics Committee of the Public Health Centre "Zivinice". Demographic, clinical and laboratory data of patients were collected during period from February to July 2016.

Criteria for inclusion in the study for both sexes were: high blood pressure, high blood glucose levels, $18-80$ years of age, non-smokers, not drinking alcohol, last meal consumed before 6 or more hours. Criteria for exclusion from the study was: a disease that can cause disturbance of potassium and glucose levels (except for diabetes), surgical procedures on the heart and blood vessels, diseases of the pancreas, the existence of recent acute stress reactions, use of medicines that can affect the level of blood glucose and cardiac arrhythmias.

Data were collected upon patients' arrival in the Emergency Medical Service, as well as 30 minutes after administration of furosemide.

Patients were selected consecutively, and analysis was carried out as follows:

(1) Clinical evaluation of each patient included a medical history about the presence of the aforementioned associated symptoms: chest pain, shortness of breath, headache, nausea and vomiting, epistaxis, anxiety, convulsions, focal neurologic deficit (numbness or weakness in the extremities, speech disorder, balance disorder, confusion, and loss of consciousness) and visual disturbances. Also, data was collected from the patients regarding the duration of hypertension and antihypertensive treatment.

(2) An analysis of the arterial blood pressure values were measured in the Emergency Medical Service. Arterial blood pressure was measured to all patients using sphygmomanometer (apparatus for measuring blood pressure) "Riester diplomat" which is produced in Germany. Arterial blood pressure was measured, in the sitting position after resting for 5 minutes, using standard equipment and techniques. A check of blood pressure was performed 30 minutes after application of therapy.

(3) An analysis of electrocardiography (ECG) was performed in the Emergency Medical Service. Electrocardiogram was performed to all patients on electrocardiograph "Schiller AT-2 plus" produced in Switzerland with 12 conventional drains under optimal conditions (shooting speed of $25 \mathrm{~mm} / \mathrm{s}$, a calibrated gauge deflection of $1 \mathrm{mV} / 10 \mathrm{~mm}$ ). We analyzed arrhythmia (tachycardia, bradycardia, AV block, premature, atrial and ventricular flutter and flicker) and ischemia.

(4) We analyzed results of hypertension therapy (30 minutes after the administration of the therapy was performed a control measurement of arterial blood pressure and on the basis of that was assessed the success of the therapy).

(5) A comparison of ECG was performed before and after treatment.

(6) Blood glucose was measured before and after the treatment, and it has been performed evaluation and statistical analysis of an impact of medicines on the blood glucose levels. The measurement was performed using glucometer "Wellion Calla Light" and using strips produced in Austria. Blood was taken from the fingertip and finger disinfection was carried out using Asepsol.

BMI (body mass index) was determined to all patients according to the formula for the measuring of the BMI:

\begin{tabular}{|c|c|}
\hline \multirow{2}{*}{$\mathrm{BMI}=$} & mass $(\mathrm{kg})$ \\
\hline & (height (m)) squared \\
\hline \multirow[b]{2}{*}{$\mathrm{BMI}=$} & mass (lb) $\times 703$ \\
\hline & (height (in)) squared \\
\hline \multirow{2}{*}{$\mathrm{BMI}=$} & mass (lb) $\times 4.88$ \\
\hline & (height (ft)) squared \\
\hline
\end{tabular}

Figure 1. Shows how to calculate body mass index. 
Medicines which were used in the study were: Furosemide $20 \mathrm{mg} / 2 \mathrm{ml} \mathrm{x} 2$ ampoules i.v. (Lodix, manufacturer Bosnalijek, Bosnia and Herzegovina).

All data were analyzed using descriptive statistics, where numerical data was presented using appropriate measures of the central tendency and measures of dispersion, also all numerical data are presented in appropriate tables and graphs.

Nonparametric methods and tests were used in order to calculate statistical significance and those are: for calculation of differences within groups was used $x^{2}$ test, while for calculation of difference between groups besides $x^{2}$ test was also used Kruskall-Wallis test, and if there was a statistically significant difference between the groups, an additional testing was carried out between groups using the MannWhitney $U$ test; for parametric data a difference between groups was calculated using single -factor analysis of variance (ANOVA) followed by Tukey's HD test if there were differences between the groups, and also Student's ' $t$ "' test for dependent samples; for calculation of the testing before and after prescribed therapy was used Wilcoxon rank test; while for calculation of correlation where it was necessary it was used Pearson and Spearman correlation test.

The statistical hypotheses were tested at the level of $\alpha=$ 0.05 , i.e the difference between groups in the sample is considered significant if $p<0.05$. Statistical analysis was performed using programmatic support of biomedical application software called " MedCalc for Windows version 12.4.0 " Copyright (C) 1993 to 2013, and for the most part using the software "SPSS Statistics 17.0," Copyright (c) 1993-2007.

\section{Results}

The study included a total of 120 patients, of whom 59 were men (49.1\%) and 61 women (50.9) (Table 1).

Table 1. Distribution of respondents by sex.

\begin{tabular}{lll}
\hline & The total number of & BMI \\
\hline Men & 59 & 49.1 \\
Women & 61 & 50.9 \\
Total & 120 & 100.0 \\
\hline
\end{tabular}

$\left(\chi^{2}=11.025 ; \mathrm{df}=1 ; \mathrm{p}=0.7\right)$
This difference in the frequency of men and women was not statistically significant $\left(\chi^{2}=11.025 ; \mathrm{df}=1 ; \mathrm{p}=0.7\right)$. The average age of men is 52 years of age while of women is 50.8 years of age.

BMI in all observed patients ranged from 19 to 38 , with an average value of 26.98 and a standard deviation of 4.297.

The majority of patients had BMI 30 and 22 of them had BMI (18.3\%). There was no statistically significant difference in the frequency of certain values of BMI between men and women

$\left(\chi^{2}=53.665 ; \mathrm{df}=54 ; \mathrm{p}=0.487\right)$. The high blood pressure was higher when the value of $\mathrm{BMI}>25$, while it was lower when the value of $\mathrm{BMI}<25$. It was determined a statistically significant correlation of the elevated BMI and hypertension $(\mathrm{p}<0.001)$.

Looking at all the three groups of patients, it can be noticed that the maximum value of arterial blood pressure upon arrival at the Emergency Medical service had patients suffering from hypertension and diabetes, where the average value of arterial blood pressure was 173/113 $\mathrm{mmHg}$. Patients suffering from hypertension had an average value of arterial blood pressure 166/105 $\mathrm{mmHg}$, while patients with high arterial blood pressure without diagnosed hypertension had an average value of arterial blood pressure 159/103 $\mathrm{mmHg}$.

After treatment with furosemide, the lowest value of arterial blood pressure had patients with an elevated arterial blood pressure without diagnosed hypertension with an average value of $118 / 80 \mathrm{mmHg}$ (Table 2).

The largest number of hypertensive crisis was in a group of patients suffering from hypertension ( 8 cases), while in the group of patients who are suffering from hypertension and diabetes were 4 cases. In the group of patients who had high blood pressure without diagnosed hypertension and diabetes there were no cases of hypertensive crisis.

Additional comparisons using the Tukey HSD test solar of some examined groups showed that the group of patients suffering from hypertension is significantly different from the other groups when it comes to the hypertensive crisis.

Table 2. Differences between the groups regarding values of blood pressure after treatment.

\begin{tabular}{llll}
\hline & Mann-Whitney $\mathbf{U}$ & Significance level & The average value of arterial blood pressure \\
\hline Patients suffering from hypertension & $\mathrm{Z}=-6,286$ & $\mathrm{p}<0,001$ & $130 / 95$ \\
$\begin{array}{l}\text { Patients suffering from hypertension and diabetes } \\
\begin{array}{l}\text { Patients suffering from high blood pressure without } \\
\text { diagnosed hypertension }\end{array}\end{array}$ & $\mathrm{Z}=-1,726$ & $\mathrm{p}=0,084$ & $138 / 103$ \\
\hline
\end{tabular}

Additional calculations of Mann-Whitney's U-test between individual test groups, using Bonferroni's adjustment of statistical significance $(\alpha=0.05 / 3=0.017)$ it was determined a statistically significant difference $(\alpha<0.017)$ among all observed groups.

According to ANOVA analysis for all three observed groups of patients, after treatment with furosemide there is no statistical significance in the incidence of arrhythmias between the groups where $p=0.202$ (Table 3 ).

When looking within each group between men and women, there is no statistical significance in the incidence of arrhythmias before and after therapy, where $p=0.709$. The most common arrhythmic disorder was supraventricular tachycardia and a total of 7 cases $(5.7 \%)$. 
Table 3. ECG results in the examined groups of patients.

\begin{tabular}{|c|c|c|c|}
\hline & Normal results & Arrhythmia & Ischemia \\
\hline Patients suffering from hypertension & 35 & 5 & 0 \\
\hline Patients suffering from hypertension and diabetes & 36 & 4 & 0 \\
\hline Patients suffering from high arterial blood pressure & 37 & 3 & 0 \\
\hline Total & 108 & 12 & 0 \\
\hline
\end{tabular}

$\left(\chi^{2}=32.549 ; \mathrm{df}=9 ; \mathrm{p}=0.202\right)$

After admission to the Emergency Medical Service, the highest level of blood glucose was noticed in the group of patients who are suffering from hypertension and diabetes, with an average value of $11.9 \mathrm{mmol} / \mathrm{l}$, while in the group of patients who are suffering from high arterial blood pressure without diagnosed hypertension and diabetes, the average blood glucose value was the lowest $6,7 \mathrm{mmol} / 1(\mathrm{p}=0.09)$ (Table 4).

Table 4. Demonstrates a value of blood glucose upon arrival to the Emergency Medical Service.

\begin{tabular}{|c|c|c|c|c|}
\hline The group of patients & Medium value & Standard deviation & The lowest value & The highest value \\
\hline Patients suffering from hypertension & 7.1 & 4.340 & 4.0 & 8.2 \\
\hline Patients suffering from hypertension and diabetes & 11.9 & 4.039 & 7.1 & 18.4 \\
\hline Patients suffering from high arterial blood pressure & 6.7 & 4.420 & 4.2 & 7.3 \\
\hline
\end{tabular}

ANOVA: $\mathrm{F}(3.156)=7.864 ; \mathrm{p}=0.09$

It is observed that after treatment with furosemide, there is no statistically significant difference in blood glucose values between the two sexes, inside each group $\mathrm{p}<0.0823$.

Observed between groups there is no statistically significant difference in an increase of blood glucose after treatment with furosemide $(\mathrm{p}<0.09)$. Looking at the summary for all three groups of patients, the average value increase of blood glucose after treatment with furosemide is $0.7 \mathrm{mmol} / \mathrm{l}$, which is not statistically significant $(\mathrm{p}=0.3)$.

\section{Discussion}

An arterial hypertension represents permanent increase of systolic and/or diastolic blood pressure above the established limits for physiological or normal arterial blood pressure. Hypertension often makes no discomfort to the patient, and it can remain uncovered for a very long time. Hypertension is the most severe cardiovascular disorder in European countries with high national income, where hypertension was observed in $20 \%$ to $50 \%$ of the adult population [4].

A study conducted in the UK during period from 1994 to 1998, says that the incidence of hypertension is around $37 \%$ in the population. Male gender and age were closely associated with hypertension. It was determined that half of the respondents knew that they are suffering from hypertension, but they do not use antihypertensive therapy (Webeer, 2005). In our study, men make up $49.1 \%$ of patients suffering from hypertension with average age of 52 years. Women make up $50.9 \%$ of patients suffering from hypertension, with an average age of 50.8 years [5].

More than half the adult population is overweight (BMI from 25 to 29.9) or obese (BMI > or $=30)$. The combination of high BMI with high arterial blood pressure is statistically significant (Brown, 2000). These studies are consistent with the results of our study [6].

In the UK, about half of the middle aged people have high blood pressure. Most patients have a value of blood pressure up to $160 / 100 \mathrm{~mm} \mathrm{Hg}$, however 1 of 20 patients suffering from hypertension have a blood pressure value greater than $160 / 100 \mathrm{mmHg}$ (Kenny, 2012). In our study, the average value of arterial blood pressure was $173 / 113 \mathrm{mmHg}$, which is little bit higher than it was presented in a study conducted in the UK [7].

In all three groups, furosemide is administered through parenteral therapy and a dose of $40 \mathrm{mg}$ is injected intravenously. In the study conducted by Mr. Osmanović by administrating furosemide and diazepam, there has been a decrease in the value of high systolic blood pressure by 35.88 $\mathrm{mmHg}$, while diastolic blood pressure was decreased by $27.14 \mathrm{mmHg}$.

In the study, which we conducted, a group of patients which had a high arterial blood pressure without diagnosed hypertension and diabetes, had a systolic blood pressure reduced by $41 \mathrm{mmHg}$ and diastolic pressure by $23 \mathrm{mmHg}$. In our study, diabetes was the most common co-morbidity in $33 \%$ of patients. Diabetes and obesity were the most present co-morbidities either individually or in combination in hypertensive patients, while significantly less present were in normotensive patients [8].

A study conducted in the UK during period from 1994 to 1998 , says that the incidence of hypertension is around $37 \%$ in the population. Male gender and age were closely associated with hypertension. It was determined that half of the respondents knew that they are suffering from hypertension, but they do not use antihypertensive therapy (Webeer, 2005). In our study, men make up $49.1 \%$ of patients suffering from hypertensive heart disease with average age of 52 years. Women make up $50.9 \%$ of patients suffering from hypertensive heart disease, with an average age of 50.8 years [9].

An analysis of arterial hypertension complicated with the hypertensive crisis was carried out in Moscow. It was discovered that hypertensive crisis has increase by $14 \%$ during the period from 2005 to 2009. Number of 
hypertensive crisis has been increased among people of younger age (18-35 years of age). Cerebrovascular complications of hypertensive crisis happen to patients depending on their age, among male patients it was noticed maximum value between $36-74$ years of age while in female patients older than 75 years. The largest number of hypertensive crisis in our study was noticed in a group of patients suffering from hypertensive heart disease without diagnosed diabetes [10].

In our study, supraventricular tachycardia is the most common disorder of the heart rhythm (5.7\%), which is less in relation to the study conducted in the European Union where out of 91.237 patients only $197(0,22 \%)$ of them had paroxysmal supraventricular tachycardia after use of furosemide [11]. This paper shows that furosemide does not significantly affect on to the frequency of cardiac arrhythmias.

In our study, an increase of blood glucose levels observed in all three groups after treatment with furosemide is only 0.7 $\mathrm{mmol} / \mathrm{l}$ on average, which has no statistical significance. A study conducted by Lind shows that furosemide increases the concentrations of blood glucose by $0.3 \mathrm{mmol} / 1$. Our study compared to Lindov showed a 2.5 times greater increase in blood glucose, but still does not have statistical significance [12]. In our study it is concluded that use of furosemide does not lead to a significant increase in blood glucose levels, and it can be safely used in the case of fast reduction of the high arterial blood pressure in both sex.

Diabetic patients are more likely to develop high blood pressure. There are several reasons for such a high frequency of hypertension in diabetic patients. Among the most common reasons are gender, age, combination of essential hypertensive heart disease with diabetes, hyperinsulinemia and proteinuria, obesity. Around $30 \%$ of people suffering from diabetes have high blood pressure [13]. This is consistent with our study, in which a third of patients $(33 \%)$ are associated with hypertensive heart disease and diabetes.

\section{Conclusion}

As furosemide decreases the pressure within the blood vessels, it is often used to treat high blood pressure, usually when other blood pressure lowering medicines have not been effective enough. Furosemide is first antihypertensive medicine so patients who use it to treat hypertension must be careful to avoid dehydration and extensive loss of minerals. Furosemide may be used alone or in combination with other antihypertensive agents. Furosemide is a very effective medicine for the rapid lowering of blood pressure.
Furosemide is safe for the treatment of hypertension in diabetic patients. It does not cause an increase in blood glucose levels.

\section{References}

[1] S. Gamulin, "Patofiziologija", Medicinska naklada. Zagreb,2011, pp. 493-50.

[2] H. Brown et all, " Body mass index and the prevalence of hypertension and dyslipidemia", [WWW] http://www.ncbi.nlm.nih.gov/pubmed/.

[3] E Merck, " The Merck Manual of Diagnosis and Therapy", Merck Manuals, 2011, pp. 103-105.

[4] P. Kumar, “ Kumar and Clark's Clinical Medicine”, Saunders ltd., 2012 vol. 11, pp.1243-1250.

[5] JH. Bauer and WC. Gauntner, "Effect of potassium chloride on plasma renin activity and plasma aldosterone during sodium restriction in normal man", Kidney Int., 1979, pp. 246-30.

[6] T. Kenny, “ High blood pressure (hypertension)”, [WWW] http://www.patient.co.uk.

[7] E. Osmanovic, "Novotkrivena, neliječena i neadakvatno tretrirana hipertenzija kao veliki javno zdravstveni problem u hitnoj pomoći”, 2013, pp. 56-67.

[8] LS. Webber and AL Bedimo-Rung, "The obesity epidemic: incidence and prevalence", J Lo State Med Soc., vol 11, 2005, pp.157.

[9] L. Lind, C. Berne, T. Pollare and H. Lithell, "Metabolic effects of anti-hypertensive treatment with nifedipine or furosemide: a double-blind, cross-over study", Journal of Human Hypertension, vol. 9(2), 1995, 137-141.

[10] Calhoun DA et al (2008) Resistant hypertension: diagnosis, evaluation, and treatment. A scientific statement from the American Heart Association Professional Education Committee of the Council for High Blood Pressure Research. Hypertension 51:1403.

[11] Pollare T, Lithell H, Selinus I, Berne C. Sensitivity to insulin during treatment with atenolol and metoprolol: a randomised, double blind study of effects on carbohydrate and lipoprotein metabolism in hypertensive patients. Department of Geriatrics, Uppsala University, Sweden. 2014:125:456-459.

[12] FM. Sacks et al., “ Effects on blood pressure of reduced dietary sodium and the dietary approaches to stop hypertension (DASH) diet”, NEJM, vol. 344, pp. 3-10.

[13] O. Samuelsson," Hypertension in middle-aged men",. Acta Med Scand Suppl., 2000, 702:1-79. 